\title{
Use of Bayesian MUNE to show differing rate of loss of motor units in subgroups of ALS
}

Running Title: Subgroups of ALS

Baumann, F. ${ }^{1,2}$, Henderson, R.D. ${ }^{12}$, Ridall, P.G. ${ }^{34}$, Pettitt, A.N. ${ }^{4}$, Pamela A. McCombe ${ }^{1,2^{*}}$

${ }^{1}$ Department of Neurology, Royal Brisbane \& Women's Hospital, Queensland, Australia

${ }^{2}$ University of Queensland Centre for Clinical Research, University of Queensland, Australia

${ }^{3}$ Department of Mathematics and Statistics, University of Lancaster, UK

${ }^{4}$ Discipline of Mathematical Sciences, Queensland University of Technology

* Correspondence to:

Pamela McCombe, University of Queensland, Centre for Clinical Research, Queensland, Herston Campus, 4029, Queensland, Australia

Email: pamela.mccombe@uq.edu.au

Total Number of Words - 


\section{Summary:}

To evaluate differences among patients with different clinical features of ALS, we used our Bayesian method of motor unit number estimation (MUNE). We performed serial MUNE studies on 44 subjects who fulfilled the diagnostic criteria for ALS during the course of their illness. Subjects were classified into three subgroups according to whether they had typical ALS ( with upper and lower motor neurone signs) or had predominantly upper motor neurone with only minor LMN feature, or predominantly lower motor neurone signs with only minor UMN signs. In all subjects we calculated the half life of MUs, defined as the expected time for the number of MUs to halve, in one or more of the abductor digiti minimi (ADM), abductor pollicis brevis (APB) and extensor digitorum brevis (EDB) muscles. The mean half life of motor units was less in subjects who had typical ALS with both upper and lower motor neurone signs than in those with predominantly upper motor neurone weakness or predominantly lower motor neurone weakness. In 18 subjects we analysed the estimated size of the MUs and demonstrated the appearance of large MUs in subjects with upper or lower motor neurone predominant weakness. We found that the appearance of large MUs was correlated with the half life of MUs.

Key words: ALS, exponential decay, mathematical models, motor unit, MUNE 


\section{Introduction}

Amyotrophic Lateral Sclerosis (ALS) is characterized by progressive loss of upper and lower motor neurones. The pathogenesis of ALS is unknown but inherited abnormalities of neuronal proteins are increasingly seen to be important [1]. The clinical picture of ALS results from dysfunction of both UMNs and LMNs. There has been debate as to whether the death of lower motor neurones (LMNs) is secondary to dying back of axons or dying forward of upper motor neurones (UMNs) or a combination of the processes [2].

ALS is diagnosed on clinical grounds for which there are accepted criteria [3] . There are other diseases of motor neurones, which do not fulfill these criteria, with pure UMN disease (primary lateral sclerosis) or pure LMN weakness (progressive muscular atrophy). However, even when defined according to the standard criteria [3], ALS is heterogeneous with respect to whether patients have typical ALS with mixed upper and lower motor neurone signs or whether UMN or LMN signs are predominant [4-7]. Clinical distinctions are important because it is possible that subjects with different clinical features have different underlying pathophysiology.

One pathophysiological finding is that large MUs that can be demonstrated by needle EMG in ALS [8]. This is thought to occur because after denervation of muscle, there is often re-innervation due to collateral sprouting of terminal branches of surviving axons. MU size in ALS has also been studied with decomposition-based quantitative electromyography (DQEMG) [9]. However, there have been no studies of the size of 
the entire population of motor unit action potentials (MUAPs) in ALS and the relationship of change in size of MUs to the rate of progression of disease.

We have developed a Bayesian statistical technique of motor unit number estimation (MUNE) that gives an estimate of the number of MUs in a muscle [10;11]. As well as estimating the number of MUs, our MUNE technique also estimates the size of all the surface-recorded MUAPs that contribute to the CMAP. We have performed a large study with serial MUNE recordings from patients with ALS, to compare the rate of loss of MUs in different clinical subtypes and different muscles and to evaluate the changes in size in MUs as disease progresses.

\section{Methods}

\section{Subjects and clinical assessment}

We recruited ALS patients who were attending the Motor Neurone Disease multidisciplinary clinic at the Royal Brisbane and Women's Hospital (RBWH). The study was approved by the Hospital Ethics Committee and all subjects gave written consent prior to testing. ALS patients met the modified El Escorial criteria for probable or definite ALS during the course of their disease [3]. We noted the age at onset of ALS, site of onset as bulbar, upper limb (UL) or lower limb (LL) and length of symptom duration before the first visit (in months).

The presence of UMN and LMN signs was evaluated. Signs of UMN involvement were taken to be spastic dysarthria, increased jaw jerk, emotional lability, hyperreflexia in the limbs, increased muscle tone, and clonus. Signs of LMN 
involvement were taken to be muscle atrophy and fasciculation. Patients with typical ALS with mixed UMN and LMN signs were grouped as typical ALS (ALS-typical).

Patients with predominantly UMN signs were designated as UMN dominant type (UMN-D). Patients with UMN-D had symptoms less than 4 years, and disability due predominantly to UMN signs but with minor EMG denervation or LMN signs on examination. In these patients LMN signs of wasting and fasciculations limited to one or two muscles or minor denervation on EMG limited to sparse fibrillation potentials, positive sharp waves or minor MU potential remodelling on one or two muscles [4]. In assigning subject to UMN-D we did not include patients with clinically pure PLS [4].

Patients with predominantly LMN signs were designated LMN dominant type (LMND). Patients with LMN-D had symptoms and disability due to prominent lower motor signs (muscle atrophy, fasciculations) at the time of first study, with no or minor UMN signs (emotional lability, hyperreflexia, spasticity). LMN-D patients were distinguished from pure adult onset LMN syndromes such as progressive muscular atrophy (PMA) patients who have disease duration of at least 4 years and absence of UMN signs [12].

Neurophysiology

MUNE studies were performed in three different nerve/muscle combinations: median nerve / abductor pollicis brevis (APB) muscle, ulnar nerve/ abductor digiti minimi (ADM) / ulnar nerve and peroneal nerve /extensor digitorum brevis (EDB) muscle. 
Surface recordings using the belly-tendon configuration were made from APB, ADM, and EDB muscles with disposable silver pre-gelled, 20mm diameter self adhesive electrodes (Nicolet Biomedical, Madison, Wisconsin). All studies were performed using a Nicolet Viking IV machine. The recording electrode was placed over the middle of the belly of the muscle (with attention to the muscle end plate). Before placing the electrodes, the skin was cleaned to prevent high or mismatching impedance between the electrodes. In all studies, the skin temperature was recorded with a surface probe and was maintained above $31{ }^{\circ} \mathrm{C}$ for the hand and $29^{\circ} \mathrm{C}$ for the foot. The muscle under testing was restrained with a Velcro strap, and the audiometer was used to detect movement [13]. The active stimulating electrode was taped approximately $7 \mathrm{~cm}$ from the active recording electrode. The stimulus intensity was measured as current (mA) in constant voltage mode, and stimuli were $0.1 \mathrm{~ms}$ in duration. The frequency of stimulation was $2 \mathrm{~Hz}$.

For MUNE studies, a stimulus response curve with 1000 stimuli was first obtained as described previously [14;15]. The size of the stimulus required to produce a maximal CMAP was determined with standard NCS. For the stimulus response curve, the maximal CMAP was obtained with a stimulus strength sufficiently above the maximal (at least 10-20\%) that small movements of stimulating electrodes would be unlikely to affect the maximal CMAP. For each study the minimum and maximum stimulus intensity was determined before commencing collection of the stimulus-response curve by gradually increasing the stimulus intensity with at least 1000 stimuli. A software modification supplied by Nicolet Biomedical (Madison, Wisconsin) was used to collect the stimulus response curves, by automatically evoked incremental stimuli. The CMAP amplitude measurements were automatically calculated from 
baseline to negative peak. The areas and durations of the negative phase of the CMAP were measured from onset to baseline crossing.

\section{MUNE calculations}

Bayesian MUNE analysis was applied to the stimulus response curves, as previously published [10;11]. In the present study, on the basis of our experience with the technique, we have modified the analysis by making a direct recording of the baseline noise (rather than estimating this in the model), by making the variability of the CMAP be the same across the entire CMAP scan, rather than increasing linearly with the number of units firing, and by prohibiting MUs with excitability curves that extend across the whole stimulus range.

The MUNE method is based on mathematical model of MU activation, and uses the data from the stimulus response curve to estimate the unknown parameters of the model [16]. These parameters include the number of MUs and the size of the MUAPs. The size of the MUAPS are obtained by first obtaining the most probable number of MUs and using this as a fixed value in the model to estimate the average sizes of individual MUAPs over a further 10,000 iterations of the programme.

\section{Calculation of half-life}

The modal value of the posterior distribution of the number of MUs at each study was used to calculate the half life of MUs according to an exponential decay model in the nerve with more than 3 studies. The half life of the MU number was calculated as loge2 / (exponential rate of decline or decay constant). 
Half life according to clinical group

To determine whether the half lives of MUs in ALS was related to clinical features, the mean half lives of MUs among the three clinical groups was compared. The mean survival for these groups was also calculated.

Studies of MUAP size at different time points

In ALS subjects and healthy controls, we obtained histograms of individual estimated MU sizes for three different time points. We analysed these according to the clinical subtypes of ALS. For each study we calculated the median value of the MUAP size. We also assigned a value of size of 1000 microVms as a cut-off for large MUs, and for each study we calculated the percentage of MUs that had an area $>1000$ microVms.

\section{Statistical methods}

Descriptive statistics are presented as mean and standard deviation or standard error of mean for continuous variables and proportions for categorical variables. Multiple comparisons among different nerves and clinical subtypes were made by one-way analysis of variance (ANOVA).

To see if the percentage of large MUs (defined as $>1000$ microVms) was associated with the half life, we calculated the correlation co-efficient between the two measures in data from the second study at the midpoint of disease.

\section{Results}

Subjects and clinical features 
We studied 44 subjects with a diagnosis of ALS. One of these patients had familial ALS with a rare SOD1 mutation with long survival [17] and the other subjects had sporadic ALS. Other results from this cohort have been published previously (Baumann et al. submitted). All subjects had MUNE studies at least 4 times at intervals of three to four months. Some patients had two muscles studied at each neurophysiology session. Table 1 shows the clinical features of ALS subjects including the age, gender, site of onset, time from onset of symptoms at the start of study and survival time. The mean (SD) age of the subjects was 59 (11) years. There were more males $(n=30)$ than females $(n=14)$.

On the basis of clinical observation, 18 patients were classified as having typical mixed ALS, 12 had predominant UMN signs (UMN-D) and 14 had predominant LMN signs (LMN-D). This classification was made prior to MUNE testing.

The half life in clinical subtypes of ALS

The mean (SD) half-life of MUs in all muscles (57 studies) in subjects with ALStypical, those with LMN-D and those with UMN-D were 235 (151), 448 (219) and 979 (368) days, respectively. The half life of MUs was significantly less in subjects with ALS-typical than in subjects with LMN-D or UMN-D (Figure 1).

In the typical ALS group, we studied 16 ADM (55\%), 7 APB and 6 EDB muscles. In LMN- D group, 12 ADM (68\%), 1 APB and 4 EDB muscles were studied. In UMN D group, 8 ADM (66\%) and 4 APB muscle studies were used to calculate half life of MUs. Therefore the majority of studies were from ADM muscle in each subgroup. 
The mean (SD) survival times of subjects with ALS-typical, LMN-D and UMN-D were 999 (311), 1443 (679) and 1614 (608) days, respectively. The survival time of subjects with ALS-typical was significantly shorter than those with LMN-D or UMND type (Figure 2).

We also compared the half lives of MUs of men $(n=30)$ and women $(n=14)$ as shown in Table 2 for the whole group and for each of the subgroups. There was no significant difference in half life of MUs in males (mean=419 days) and females (mean=366 days) $(\mathrm{p}=0.5)$.

Studies of MUAP size at different time points:

For this part of the study we used subjects who had serial testing of the ulnar nerve/ ADM muscle. There were 8 subjects with ALS-typical, 4 with UMN-D, 4 with LMND and 8 healthy controls. For this analysis we used the MUNE studies at three timepoints. The mean interval from onset of symptoms to the first study was 14 (SD 6) months for typical ALS, 22 (SD 6) months for UMN-D patients and 20 (SD 11) months for LMN-D patients. The second studies were done at a mean (SD) of 6 (2), 7 (4) and 8 (3) months after the first study for typical, UMN-D, and LMN-D respectively. The third studies were done at a mean of 5 (2), 9 (2) and 11 (9) months after the second study for typical, UMN-D, and LMN-D respectively.

For each subject, at each time-point the median and range in MUAP size was calculated. Figure 3 shows examples of the distribution of MUAP sizes and 
representative subjects with ALS-typical, UMN-D and LMN-D types of disease, each at two time-points.

The mean values of the median MU size and the percentage of large MUs at each time-point for each type are shown in Figure 4. In the three groups of subjects with ALS, there was a large range of values for MU size, with some subjects having large median size and some subjects having a large percentage of large MUs compared to healthy subjects. This was most obvious in the UMN-D and LMN-D groups which also had larger MUs than those in the ALS-typical group. At the third study, there was a decline in the percentage of large units in 3 of the 8 subjects with typical ALS. In the groups with UMN-D and LMN-D the percentage of large units at the third study was greater than at the previous studies for all subjects.

For each subject we calculated the ratio of the values at the second and third timepoints to the values at the first time-point. For each group we then calculated the mean and standard deviation of these ratios and these are shown in Table 3.

Relationship of frequency of large MUs to rate of progression

To determine if the percentage of large MUAPs was related to the half-life of MUs we calculated the percentage of large MUAPs (defined as being greater than 1000 microVms) at the second study. We chose to use the data from the second study because at the third study some subjects showed a decline in the number of large MUs, as can occur at the pre-terminal stage of disease. We plotted the percentage of large MUs against half life of MUs in 18 patients (Figure 5). There was a significant correlation between percentage of large MUAPs and half life of MUs $(r=0.70)$. 


\section{Discussion}

In this study we have used our MUNE technique to show that the half-life of motor units and the accumulation of large motor units varies among subtypes of ALS. The results are based on our Bayesian MUNE method which is based on a model of motor unit activation, and leads to an estimate of the numbers and size of MUs in a muscle. We have previously explained the biological basis of our model and the underlying assumptions, and how we account for the variables in MU activation including variation in the threshold of axons and variation in the size of motor units $[16 ; 18]$. We have previously shown with serial studies of the number of MUs in a muscle, that the loss of MUs is well-fitted by an exponential decay curve (Baumann et al. unpublished data). The demonstration that MU loss follows an exponential decay allows us to estimate the half-life of MUs.

We found that patients with different clinical features differ in the rate of loss of MUs. In patients with typical ALS (with UMN and LMN signs) the half life of MUs was less than in subjects with UMN or LMN predominant disease. Our study of the halflife provides electrophysiological evidence that supports clinical studies showing that patients with predominance of UMN involvement have a more benign course [19] and longer survival than subjects with typical ALS [20] and that subjects with LMN weakness have a slower rate of progression than subjects with typical ALS [12]. Although there are differences in the prevalence of ALS in men and women, and men and women differ in the site of onset of disease, with bulbar onset being more 
common in older women [21] there was no difference between men and women in the half lives of MUs in the subjects that we studied.

We also used our MUNE method to study the size of MUAPs in ALS subjects, although this study has the limitation that recording from surface electrodes may underestimate the size of distant action potentials. MUs are known to vary in size from moment to moment [22], so in our model we allow MUs to vary in size, and the results we present are the average of 10,000 estimations.

There was an increase in the percentage of large motor units over time in subjects with all subtypes of ALS, with the percentage of large MUAPS correlated with the half life. This was variable among subjects reflecting the heterogeneity of disease. However, in a few of the subjects with typical ALS, there was a decline in the number of large MUs at the third study. There was an increase in the median size of MUs, particularly in subjects with UMN-D and LMN-D type of disease, and in some subjects with ALS-typical. These findings are consistent with current understanding of ALS [8;23;24] where collateral sprouting leads to an increased fibre density of MUs [25;26]. We found that the increase in MUAP size in the early stages of lesion, reflecting re-innervation, was much greater in LMN predominant subtype than typical ALS, consistent with previous reports [27]. These UMN-D and LMN-D subjects differ from typical ALS subjects in having a longer half life, and were also studied at longer times after onset of disease. We suggest that the slower and longer disease process allows collateral sprouting to occur in these subjects. We found that the percentage of large MUs was related to the half-life of MUs. 
In previous studies, a modest increase in MU size was found using the multiple point stimulation MUNE method [28-30] . A previous multicentre serial MUNE study using the Poisson statistical method did not find an increase in mean MUAP size over time [31], perhaps because the effect of MU variability could not be included in the calculation. Others have shown an increase in MU size over time, using the MPS method which measures the size of a sample of MUs, rather than the whole population as is the case with our method, although in some subjects the size of the MUs declines at the end stage of disease [9;30].

These differences in length of survival, rate of progression and the accumulation of large MUs could indicate that there are underlying pathophysiological differences among these groups. Indeed, post-mortem studies have found that subjects with typical ALS differ from those with LMN predominant form of ALS in the pattern of neuronal loss, providing evidence that the clinical signs of disease reflect the pattern of neuronal loss in ALS [32]. In UMN dominant ALS, a benign LMN impairment involving only few motor units and leaving the others intact was a common feature [33]. Similarly a post-mortem study showed LMN loss was minimal in patients whose motor manifestations had been predominantly UMN type [34]. Recently subjects with UMN predominant disease have been found to have genetic variation in the KIFAP3 [35]. Although the classification into the subtypes of MND was based on clinical assessment, this reflects the clinical heterogeneity of the disease and is an approach being used by others. In summary, our MUNE analysis appears to be a feasible method to provide new insights into the pathophysiology of lower motor neuron degeneration and MU re-arrangement in ALS. 


\section{Acknowledgements}

We appreciate the effort and time of the patients and their families who were involved in this study. We thank Nicole Hutchinson for her assistance in patient recruitment.

\section{Funding}

The study was supported by the National Health and Medical Research Council, the Australian Research Council, Motor Neurone Disease Research Institute of Australia, and the Royal Brisbane \& Women’s Hospital Foundation.

\section{Abbreviations}

$\mathrm{ADM}$ - abductor digiti minimi

APB - abductor pollicis brevis

ALS - amyotrophic lateral sclerosis

CMAP - compound muscle action potential

EDB - extensor digitorum brevis

FDI - first dorsal interosseous

LMN - lower motor neurone

LL - lower limb

MN - motor neurone

MU - motor unit

MUAP - motor unit action potential

MUNE - motor unit number estimate 
Lower motor neuron degeneration in ALS

PLS - primary lateral sclerosis

PMA - progressive muscular atrophy

TA - tibialis anterior

UL - upper limb

UMN - upper motor neurone 


\section{References}

Ahmadi M, Liu JX, Brannstrom T, Andersen PM, Stal P, Pedrosa-Domellof F. Human extraocular muscles in ALS. Invest Ophthalmol Vis Sci 2010; 51: 3494-501.

Albrecht E, Kuntzer T. Number of Edb motor units estimated using an adapted multiple point stimulation method: normal values and longitudinal studies in ALS and peripheral neuropathies. Clin Neurophysiol 2004; 115: 557-63.

Andres PL, Finison LJ, Conlon T, Thibodeau LM, Munsat TL. Use of composite scores (megascores) to measure deficit in amyotrophic lateral sclerosis. Neurology 1988; 38: 405-8.

Armon C, Brandstater ME. Motor unit number estimate-based rates of progression of ALS predict patient survival. Muscle Nerve 1999; 22: 1571-5.

Bae JS, Sawai S, Misawa S, Kanai K, Isose S, Kuwabara S. Differences in excitability properties of FDI and ADM motor axons. Muscle Nerve 2009; 39: 350-4.

Baumann F, Henderson RD, Tremayne F, Hutchinson N, McCombe PA. Effects of prolonged repetitive stimulation of median, ulnar and peroneal nerves. Muscle Nerve 2010a; 41: 785-93.

Baumann F, Rose SE, Nicholson GA, Hutchinson N, Pannek K, Pettitt A, et al. Biomarkers of disease in a case of familial lower motor neuron ALS. Amyotroph Lateral Scler 2010b; 11: 486-9.

Beghi E, Chio A, Couratier P, Esteban J, Hardiman O, Logroscino G, et al. The epidemiology and treatment of ALS: Focus on the heterogeneity of the disease and critical appraisal of therapeutic trials. Amyotroph Lateral Scler 2011; 12: $1-10$.

Bjornskov EK, Norris FH, Jr., Mower-Kuby J. Quantitative axon terminal and endplate morphology in amyotrophic lateral sclerosis. Arch Neurol 1984; 41: 52730.

Bland JM, Altman DG. Statistical methods for assessing agreement between two methods of clinical measurement. Lancet 1986; 1: 307-10.

Blok JH, Ruitenberg A, Maathuis EM, Visser GH. The electrophysiological muscle scan. Muscle Nerve 2007; 36: 436-46.

Boe SG, Stashuk DW, Doherty TJ. Motor unit number estimates and quantitative motor unit analysis in healthy subjects and patients with amyotrophic lateral sclerosis. Muscle Nerve 2007; 36: 62-70.

Bromberg MB. Consensus in Motor Unit Number Estimation (MUNE). Amsterdam: Elsevier: 2003.

Brooks BR, Miller RG, Swash M, Munsat TL. El Escorial revisited: revised criteria for the diagnosis of amyotrophic lateral sclerosis. Amyotroph Lateral Scler Other Motor Neuron Disord 2000; 1: 293-9.

Brown WF, Jaatoul N. Amyotrophic lateral sclerosis. Electrophysiologic study (number of motor units and rate of decay of motor units). Arch Neurol 1974; 30: 242-8.

Clarke G, Collins RA, Leavitt BR, Andrews DF, Hayden MR, Lumsden CJ, et al. A one-hit model of cell death in inherited neuronal degenerations. Nature 2000; 406: 195-9. 
Cox DR, Oaks D. Analysis of Survival data. London: Chapman \& Hall: 1984.

Dadon-Nachum M, Melamed E, Offen D. The "Dying-Back" Phenomenon of Motor Neurons in ALS. J Mol Neurosci 2011; 43: 470-7.

Dengler R, Konstanzer A, Kuther G, Hesse S, Wolf W, Struppler A. Amyotrophic lateral sclerosis: macro-EMG and twitch forces of single motor units. Muscle Nerve 1990; 13: 545-50.

Eisen A, Kim S, Pant B. Amyotrophic lateral sclerosis (ALS): a phylogenetic disease of the corticomotoneuron? Muscle Nerve 1992; 15: 219-24.

Emeryk-Szajewska B, Kopec J, Karwanska A. The reorganisation of motor units in different motor neuron disorders. Electromyogr Clin Neurophysiol 2003; 43: 23-31.

Felice KJ. A longitudinal study comparing thenar motor unit number estimates to other quantitative tests in patients with amyotrophic lateral sclerosis. Muscle Nerve 1997; 20: 179-85.

Frey D, Schneider C, Xu L, Borg J, Spooren W, Caroni P. Early and selective loss of neuromuscular synapse subtypes with low sprouting competence in motoneuron diseases. J Neurosci 2000; 20: 2534-42.

Gordon PH, Cheng B, Katz IB, Pinto M, Hays AP, Mitsumoto H, et al. The natural history of primary lateral sclerosis. Neurology 2006; 66: 647-53.

Gouveia LO, de Carvalho M. Young-onset sporadic amyotrophic lateral sclerosis: a distinct nosological entity? Amyotroph Lateral Scler 2007; 8: 323-7.

Hansen S, Ballantyne JP. A quantitative electrophysiological study of motor neurone disease. J Neurol Neurosurg Psychiatry 1978; 41: 773-83.

Hegedus J, Putman CT, Gordon T. Time course of preferential motor unit loss in the SOD1 G93A mouse model of amyotrophic lateral sclerosis. Neurobiol Dis 2007; 28: 154-64.

Hegedus J, Putman CT, Tyreman N, Gordon T. Preferential motor unit loss in the SOD1 G93A transgenic mouse model of amyotrophic lateral sclerosis. J Physiol 2008; 586: 3337-51.

Henderson RD, Daube JR. Decrement in surface-recorded motor unit potentials in amyotrophic lateral sclerosis. Neurology 2004; 63: 1670-4.

Henderson RD, Ridall GR, Pettitt AN, McCombe PA, Daube JR. The stimulusresponse curve and motor unit variability in normal subjects and subjects with amyotrophic lateral sclerosis. Muscle Nerve 2006; 34: 34-43.

Henderson RD, Ridall PG, Hutchinson NM, Pettitt AN, McCombe PA. Bayesian statistical MUNE method. Muscle Nerve 2007; 36: 206-13.

Jillapalli D, Shefner JM. Single motor unit variability with threshold stimulation in patients with amyotrophic lateral sclerosis and normal subjects. Muscle Nerve 2004; 30: 578-84.

Kuether G, Lipinski HG: The dynamics of motor neuron degeneration in motor neuron disease. A theoretical approach.; in: Smith RA, editor: Handbook of amyotrophic lateral sclerosis. New York, Marcel Dekker, 1991, pp 391-432. Kuwabara S, Sonoo M, Komori T, Shimizu T, Hirashima F, Inaba A, et al. Dissociated small hand muscle atrophy in amyotrophic lateral sclerosis: frequency, extent, and specificity. Muscle Nerve 2008; 37: 426-30.

McCombe PA, Henderson RD. Effects of gender in amyotrophic lateral sclerosis. Gend Med 2010; 7: 557-70.

McCombe PA, Henderson RD, Ridall PG, Pettitt AN. Biological basis for motor unit number estimation through Bayesian statistical analysis of the stimulusresponse curve. Suppl Clin Neurophysiol 2009; 60: 39-45. 
Miller J, Arrasate M, Shaby BA, Mitra S, Masliah E, Finkbeiner S. Quantitative relationships between huntingtin levels, polyglutamine length, inclusion body formation, and neuronal death provide novel insight into huntington's disease molecular pathogenesis. J Neurosci 2010; 30: 10541-50.

Munsat TL, Andres PL, Finison L, Conlon T, Thibodeau L. The natural history of motoneuron loss in amyotrophic lateral sclerosis. Neurology 1988; 38: 409-13.

Polgar J, Johnson MA, Weightman D, Appleton D. Data on fibre size in thirty-six human muscles. An autopsy study. J Neurol Sci 1973; 19: 307-18.

Pun S, Santos AF, Saxena S, Xu L, Caroni P. Selective vulnerability and pruning of phasic motoneuron axons in motoneuron disease alleviated by CNTF. Nat Neurosci 2006; 9: 408-19.

Ravits J, Laurie P, Fan Y, Moore DH. Implications of ALS focality: rostral-caudal distribution of lower motor neuron loss postmortem. Neurology 2007; 68: 1576-82.

Ridall PG, Pettitt AN, Henderson RD, McCombe PA. Motor unit number estimation-a Bayesian approach. Biometrics 2006; 62: 1235-50.

Ridall PG, Pettitt AN, Friel N, McCombe PA, Henderson RD. Motor unit number estimation using reversible jump Markov chain Monte Carlo. Appl. Statist. 2007; 56: 1-26.

Rothstein JD. Current hypotheses for the underlying biology of amyotrophic lateral sclerosis. Ann Neurol 2009; 65 Suppl 1: S3-9.

Shefner JM, Cudkowicz ME, Brown RH, Jr. Comparison of incremental with multipoint MUNE methods in transgenic ALS mice. Muscle Nerve 2002; 25: 39-42.

Shefner JM, Cudkowicz ME, Zhang H, Schoenfeld D, Jillapalli D. The use of statistical MUNE in a multicenter clinical trial. Muscle Nerve 2004; 30: 463-9.

Shefner JM, Reaume AG, Flood DG, Scott RW, Kowall NW, Ferrante RJ, et al. Mice lacking cytosolic copper/zinc superoxide dismutase display a distinctive motor axonopathy. Neurology 1999; 53: 1239-46.

Soraru G, D'Ascenzo C, Nicolao P, Volpe M, Martignago S, Palmieri A, et al. Muscle histopathology in upper motor neuron-dominant amyotrophic lateral sclerosis. Amyotroph Lateral Scler 2008; 9: 287-93.

Soraru G, Ermani M, Logroscino G, Palmieri A, C DA, Orsetti V, et al. Natural history of upper motor neuron-dominant ALS. Amyotroph Lateral Scler 2010; 11: 424-9.

Swash M, Schwartz MS. A longitudinal study of changes in motor units in motor neuron disease. J Neurol Sci 1982; 56: 185-97.

Talman P, Forbes A, Mathers S. Clinical phenotypes and natural progression for motor neuron disease: analys is from an Australian database. Amyotroph Lateral Scler 2009; 10: 79-84.

Terao S, Sobue G, Hashizume Y, Mitsuma T, Takahashi A. Disease-specific patterns of neuronal loss in the spinal ventral horn in amyotrophic lateral sclerosis, multiple system atrophy and $\mathrm{X}$-linked recessive bulbospinal neuronopathy, with special reference to the loss of small neurons in the intermediate zone. J Neurol 1994; 241: 196-203.

Turner MR, Parton MJ, Shaw CE, Leigh PN, Al-Chalabi A. Prolonged survival in motor neuron disease: a descriptive study of the King's database 1990-2002. J Neurol Neurosurg Psychiatry 2003; 74: 995-7. 
Van den Berg-Vos RM, Visser J, Kalmijn S, Fischer K, de Visser M, de Jong V, et al. A long-term prospective study of the natural course of sporadic adult-onset lower motor neuron syndromes. Arch Neurol 2009; 66: 751-7.

Wang FC, Delwaide PJ. Number and relative size of thenar motor units in ALS patients: application of the adapted multiple point stimulation method. Electroencephalogr Clin Neurophysiol 1998; 109: 36-43.

Weber M, Eisen A, Stewart H, Hirota N. The split hand in ALS has a cortical basis. J Neurol Sci 2000; 180: 66-70.

Wilbourn AJ. The "split hand syndrome". Muscle Nerve 2000; 23: 138.

Wohlfart G. Collateral regeneration in partially denervated muscles. Neurology 1958; 8: $175-80$.

Yamanaka K, Chun SJ, Boillee S, Fujimori-Tonou N, Yamashita H, Gutmann DH, et al. Astrocytes as determinants of disease progression in inherited amyotrophic lateral sclerosis. Nat Neurosci 2008; 11: 251-3. 


\section{Figure Legends}

\section{Figure 1. Half life of MUs according to type of ALS.}

The half life of MUs among three clinical subtypes (ALS-typical, UMN-D LMN-D ) was compared. There was significant difference in half lives among these three subtypes $(\mathrm{p}<0.05)$.

\section{Figure 2. Survival time according to type of ALS}

The mean survival time for these groups was also calculated (D). The survival time of subjects with typical ALS was significantly shorter than those with predominantly lower (LMN-D) or predominantly upper motor neurone (UMN- D) weakness.

The bottom and top of the boxes are the $25^{\text {th }}$ and $75^{\text {th }}$ percentile (the lower and upper quartiles, respectively), and the band near the middle of the box is the $50^{\text {th }}$ percentile (the median). The whiskers represent the minimum and maximum of all the data.

\section{Figure 3. Frequency distribution of MU sizes}

Examples of the distribution of single MUAP areas of a subjects with typical ALS (C, D), LMN-D disease (E, F) and UMN-D (G, H) type of disease, showing studies at the as the mid stage of disease (study 1) and end stage (study 2) of disease. MU size is given as area (micoVms). 
Dotted lines represent the distribution curves. The LMN and UMN predominant patients had very large MUs (> 3000) at the early stages (E, G) and there were almost only large MUs (> 1000), up to 7000uVms (F,H) whereas the typical ALS patient had no large $\mathrm{MU}$ at the end stage (D).

Figure 4. MUAP size in subtypes of ALS during disease progression.

The graph of the mean of the median MUs sizes (upper panel) and the mean percentage of large MUs (lower panel) in healthy controls and three groups of ALS subjects (typical ALS, UMN-D, LMN-D) at early, mid and late stages of the disease. Error bars represent \pm SD

Figure 5. The correlation of the half life of MUs and the percentage of large MUs. The percentage of large units ( $>1000$ microVms) at the second study in 18 ALS subjects was plotted against half life of MUs. There was significant correlation between percentage of large MUs and the half life of MUs ( $r=0.70)$. 
$\underline{\text { Table 1. Clinical features of ALS subjects }}$

\begin{tabular}{|l|l|}
\hline Number of subjects & \\
\hline Total number of subjects & 44 \\
\hline No (\%) males & $30(68)$ \\
\hline Age of onset and symptom duration & \\
\hline Mean (sd) Age of onset (yr) & \\
\hline Range of age of onset (yr) & $59(11)$ \\
\hline Duration of symptoms at study entry (mo) & $30-81$ \\
\hline Range of symptom onset (mo) & $15(11)$ \\
\hline Site of onset & $3-62$ \\
\hline No (\%) bulbar onset & \\
\hline No (\%) upper limb onset & \\
\hline No (\%) lower limb onset & $12(27)$ \\
\hline Clinical features & $15(35)$ \\
\hline No.(\%) with Typical ALS & $17(38)$ \\
\hline No (\%) with UMN predominant & \\
\hline No (\%) with LMN predominant & \\
\hline Survival & $18(41)$ \\
\hline Mean (sd) survival time (mo) & $14(32)$ \\
\hline Range & $12(27)$ \\
\hline No (\%) deceased at end of study & \\
\hline & $41(15)$ \\
\hline & $24(54)$ \\
\hline & \\
\hline & \\
\hline & \\
\hline & \\
\hline
\end{tabular}

† Symptom duration is from the onset of disease to the first MUNE study

‡ Survival time is calculated from the symptom onset to death in deceased patients and to the end of study in patients who were alive at the end of the study 
Table 2. Half-life of MUs according to clinical subtype and gender

\begin{tabular}{|l|c|c|c|}
\hline Group & Number & $\begin{array}{c}\text { Mean half-life } \\
\text { (days) }\end{array}$ & $\begin{array}{c}\text { SD half-life } \\
\text { (days) }\end{array}$ \\
\hline Total group males & 30 & 419 & 299 \\
\hline Total-group females & 14 & 366 & 271 \\
\hline ALS-typical males & 13 & 217 & 48 \\
\hline ALS-typical females & 5 & 204 & 210 \\
\hline LMN-D males & 9 & 503 & 117 \\
\hline LMN-D females & 5 & 297 & 397 \\
\hline UMN-D males & 8 & 652 & 369 \\
\hline UMN-D females & 4 & 654 & \\
\hline
\end{tabular}


Table 3 Ratio of median size of motor units and ratio of percentage of large motor units at study 2 and study 3 to values at first study

\begin{tabular}{|c|c|c|c|c|}
\hline Patient group & $\begin{array}{c}\text { Mean ratio of } \\
\text { median MU size at } \\
\text { second study to } \\
\text { median MU size at } \\
\text { first study }\end{array}$ & $\begin{array}{c}\text { Mean ratio of } \\
\text { median MU size at } \\
\text { third study to } \\
\text { median MU size at } \\
\text { first study } \\
\text { percent large } \\
\text { units at second } \\
\text { study to } \\
\text { percent large } \\
\text { units at first } \\
\text { study }\end{array}$ & $\begin{array}{c}\text { Mean ratio of } \\
\text { percent large } \\
\text { units at third } \\
\text { study to } \\
\text { percent large } \\
\text { units at first } \\
\text { study }\end{array}$ \\
\hline ALS-typ & $1.29(0.26)$ & $1.52(1.02)$ & $2.20(3.00)$ & $2.71(4.10)$ \\
\hline UMN-D & $1.03(0.27)$ & $1.59(0.47)$ & $1.20(0.17)$ & $1.51(0.33)$ \\
\hline LMN-D & $1.79(0.86)$ & $2.66(1.43)$ & $2.0(0.41)$ & $2.98(1.76)$ \\
\hline
\end{tabular}

Reference List

(1) Rothstein JD: Current hypotheses for the underlying biology of amyotrophic lateral sclerosis. Ann Neurol 2009; 65 Suppl 1:S3-S9.

(2) Dadon-Nachum M, Melamed E, Offen D: The "dying-back" phenomenon of motor neurons in ALS. J Mol Neurosci 2011; 43(3):470-477.

(3) Brooks BR, Miller RG, Swash M, Munsat TL: El Escorial revisited: revised criteria for the diagnosis of amyotrophic lateral sclerosis. Amyotroph Lateral Scler Other Motor Neuron Disord 2000; 1(5):293-299.

(4) Gordon PH, Cheng B, Katz IB, Pinto M, Hays AP, Mitsumoto H, Rowland LP: The natural history of primary lateral sclerosis. Neurology 2006; 66(5):647653.

(5) Gouveia LO, de CM: Young-onset sporadic amyotrophic lateral sclerosis: a distinct nosological entity? Amyotroph Lateral Scler 2007; 8(6):323-327.

(6) Talman P, Forbes A, Mathers S: Clinical phenotypes and natural progression for motor neuron disease: analysis from an Australian database. Amyotroph Lateral Scler 2009; 10(2):79-84.

(7) Beghi E, Chio A, Couratier P, Esteban J, Hardiman O, Logroscino G, Millul A, Mitchell D, Preux PM, Pupillo E, Stevic Z, Swingler R, Traynor BJ, van den Berg LH, Veldink JH, Zoccolella S: The epidemiology and treatment of ALS: Focus on the heterogeneity of the disease and critical appraisal of therapeutic trials. Amyotroph Lateral Scler 2011; 12(1):1-10.

(8) Hansen S, Ballantyne JP: A quantitative electrophysiological study of motor neurone disease. J Neurol Neurosurg Psychiatry 1978; 41(9):773-783. 
(9) Boe SG, Stashuk DW, Doherty TJ: Motor unit number estimates and quantitative motor unit analysis in healthy subjects and patients with amyotrophic lateral sclerosis. Muscle Nerve 2007; 36(1):62-70.

(10) Ridall PG, Pettitt AN, Friel N, McCombe PA, Henderson RD: Motor unit number estimation using reversible jump Markov chain Monte Carlo. Journal Royal Statistical Society Series C - Applied Statistics 2007; 56:235-269.

(11) Henderson RD, Ridall PG, Hutchinson NM, Pettitt AN, McCombe PA: Bayesian statistical MUNE method. Muscle Nerve 2007; 36(2):206-213.

(12) Van den Berg-Vos RM, Visser J, Kalmijn S, Fischer K, de VM, de J, V, de Haan RJ, Franssen H, Wokke JH, van den Berg LH: A long-term prospective study of the natural course of sporadic adult-onset lower motor neuron syndromes. Arch Neurol 2009; 66(6):751-757.

(13) Henderson RD, Daube JR: Decrement in surface-recorded motor unit potentials in amyotrophic lateral sclerosis. Neurology 2004; 63(9):1670-1674.

(14) Henderson RD, Ridall GR, Pettitt AN, McCombe PA, Daube JR: The stimulusresponse curve and motor unit variability in normal subjects and subjects with amyotrophic lateral sclerosis. Muscle Nerve 2006; 34(1):34-43.

(15) Blok JH, Ruitenberg A, Maathuis EM, Visser GH: The electrophysiological muscle scan. Muscle Nerve 2007; 36(4):436-446.

(16) McCombe PA, Henderson RD, Ridall PG, Pettitt AN: Biological basis for motor unit number estimation through Bayesian statistical analysis of the stimulusresponse curve. Suppl Clin Neurophysiol 2009; 60:39-45.

(17) Baumann F, Rose SE, Nicholson GA, Hutchinson N, Pannek K, Pettitt A, McCombe PA, Henderson RD: Biomarkers of disease in a case of familial lower motor neuron ALS. Amyotroph Lateral Scler 2010; 11(5):486-489.

(18) Ridall PG, Pettitt AN, Henderson RD, McCombe PA: Motor Unit Number Estimation-A Bayesian Approach. Biometrics 2006; 62:1235-1250.

(19) Turner MR, Parton MJ, Shaw CE, Leigh PN, Al-Chalabi A: Prolonged survival in motor neuron disease: a descriptive study of the King's database 1990-2002. J Neurol Neurosurg Psychiatry 2003; 74(7):995-997.

(20) Soraru G, Ermani M, Logroscino G, Palmieri A, D' AC, Orsetti V, Volpe M, Cima V, Zara G, Pegoraro E, Angelini C: Natural history of upper motor neuron-dominant ALS. Amyotroph Lateral Scler 2010; 11(5):424-429.

(21) McCombe PA, Henderson RD: Effects of gender in amyotrophic lateral sclerosis. Gend Med 2010; 7(6):557-570.

(22) Jillapalli D, Shefner JM: Single motor unit variability with threshold stimulation in patients with amyotrophic lateral sclerosis and normal subjects. Muscle Nerve 2004; 30(5):578-584. 
(23) Brown WF, Jaatoul N: Amyotrophic lateral sclerosis. Electrophysiologic study (number of motor units and rate of decay of motor units). Arch Neurol 1974; 30(3):242-248.

(24) Bjornskov EK, Norris FH, Jr., Mower-Kuby J: Quantitative axon terminal and end-plate morphology in amyotrophic lateral sclerosis. Arch Neurol 1984; 41(5):527-530.

(25) WOHLFART G: Collateral regeneration in partially denervated muscles. Neurology 1958; 8(3):175-180.

(26) Swash M, Schwartz MS: A longitudinal study of changes in motor units in motor neuron disease. J Neurol Sci 1982; 56(2-3):185-197.

(27) Emeryk-Szajewska B, Kopec J, Karwanska A: The reorganisation of motor units in different motor neuron disorders. Electromyogr Clin Neurophysiol 2003; 43(1):23-31.

(28) Felice KJ: A longitudinal study comparing thenar motor unit number estimates to other quantitative tests in patients with amyotrophic lateral sclerosis. Muscle Nerve 1997; 20(2):179-185.

(29) Wang FC, Delwaide PJ: Number and relative size of thenar motor units in ALS patients: application of the adapted multiple point stimulation method. Electroencephalogr Clin Neurophysiol 1998; 109(1):36-43.

(30) Albrecht E, Kuntzer T: Number of Edb motor units estimated using an adapted multiple point stimulation method: normal values and longitudinal studies in ALS and peripheral neuropathies. Clin Neurophysiol 2004; 115(3):557-563.

(31) Shefner JM, Cudkowicz ME, Zhang H, Schoenfeld D, Jillapalli D: The use of statistical MUNE in a multicenter clinical trial. Muscle Nerve 2004; 30(4):463-469.

(32) Terao S, Sobue G, Hashizume Y, Mitsuma T, Takahashi A: Disease-specific patterns of neuronal loss in the spinal ventral horn in amyotrophic lateral sclerosis, multiple system atrophy and $\mathrm{X}$-linked recessive bulbospinal neuronopathy, with special reference to the loss of small neurons in the intermediate zone. J Neurol 1994; 241(4):196-203.

(33) Soraru G, D'Ascenzo C, Nicolao P, Volpe M, Martignago S, Palmieri A, Romeo V, Koutsikos K, Piccione F, Cima V, Pegoraro E, Angelini C: Muscle histopathology in upper motor neuron-dominant amyotrophic lateral sclerosis. Amyotroph Lateral Scler 2008; 9(5):287-293.

(34) Ravits J, Laurie P, Fan Y, Moore DH: Implications of ALS focality: rostralcaudal distribution of lower motor neuron loss postmortem. Neurology 2007; 68(19):1576-1582.

(35) Orsetti V, Pegoraro E, Cima V, D'Ascenzo C, Palmieri A, Querin G, Volpe M, Ermani M, Angelini C, Soraru G: Genetic variation in KIFAP3 is associated 
with an upper motor neuron-predominant phenotype in amyotrophic lateral sclerosis. Neurodegener Dis 2011; 8(6):491-495. 